\title{
Influence of parallel computational uncertainty on simulations of the Coupled General Climate Model
}

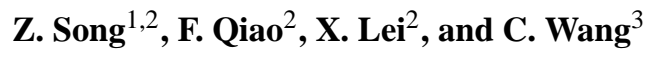 \\ ${ }^{1}$ College of Physical and Environmental Oceanography, Ocean University of China, Qingdao, China \\ ${ }^{2}$ First Institute of Oceanography, State Oceanic Administration (SOA), Qingdao, China \\ ${ }^{3}$ NOAA Atlantic Oceanographic and Meteorological Laboratory, Physical Oceanography Division, Miami, USA \\ Correspondence to: F. Qiao (qiaofl@ @io.org.cn)
}

Received: 1 October 2011 - Published in Geosci. Model Dev. Discuss.: 28 November 2011

Revised: 29 January 2012 - Accepted: 8 February - Published: 13 March 2012

\begin{abstract}
This paper investigates the impact of the parallel computational uncertainty due to the round-off error on climate simulations using the Community Climate System Model Version 3 (CCSM3). A series of sensitivity experiments have been conducted and the analyses are focused on the Global and Nino3.4 average sea surface temperatures (SST). For the monthly time series, it is shown that the amplitude of the deviation induced by the parallel computational uncertainty is the same order as that of the climate system change. However, the ensemble mean method can reduce the influence and the ensemble member number of 15 is enough to ignore the uncertainty. For climatology, the influence can be ignored when the climatological mean is calculated by using more than $30-y r$ simulations. It is also found that the parallel computational uncertainty has no distinguishable effect on power spectrum analysis of climate variability such as ENSO. Finally, it is suggested that the influence of the parallel computational uncertainty on Coupled General Climate Models (CGCMs) can be a quality standard or a metric for developing CGCMs.
\end{abstract}

\section{Introduction}

Coupled General Circulation Models (CGCMs) have been widely used since they serve as a powerful tool for climate research and prediction. However, there are still many problems faced by CGCMs, one of which is uncertainty. The IPCC-AR4's report (Meehl et al., 2007) stated that the correct analysis of model uncertainties is one of the IPCC's duties and goals. Generally, CGCM's uncertainties, which usually result from the nonlinear interaction of the component of the climatic system (Tebaldi et al., 2004; Held et al., 2002), have two types. The first one is due to uncertainty of the physical parameterization (Meehl et al., 2007; Moss and Schneider, 2000; Wittenberg and Anderson, 1998; Dorn et al., 2007), and the other one is from amplification of the computational errors (Cousins and Xue, 2001; Wang et al., 2007; Chen et al., 2008). Those results suggest that uncertain processes or parameterization schemes could cause a quite large uncertainty of the climate simulations.

A computational error, such as the round-off error, is also a major reason for the uncertainty of CGCMs. With the higher resolutions and increased physical processes in General Circulation Models (GCMs), Message Passing Interface (MPI) is widely used to improve the computational efficiency. MPI is also used to exchange the data among sub-components in the coupled system. Therefore, the analysis of the parallel computational error due to MPI is a key and necessary step to determine the coupled model stability and accuracy. Cousins et al. (2001) developed the parallel version of Princeton Ocean Model (POM) and found that there is a significant difference between the serial and parallel version of the POM. Furthermore, they concluded that the error from the data communication process via MPI is the main reason for the difference. Wang et al. (2007) studied the results of the atmospheric model SAMIL simulated with different CPUs and pointed out that the difference is chiefly caused by the round-off error. Chen et al. (2008) introduced the uncertainty of the global mean Sea Surface Temperature (SST) simulated by the Community Climate System Model Version 3 (CCSM3) with different computational platforms or different CPU configuration. Their analysis showed that the simulation results are dependent on the computational environments and the magnitude of uncertainty due to the parallel computational error could be in the same order as that of natural variations in the climate system. 
In fact, the parallel computational uncertainty related to MPI is caused by the "MPI_ALLREDUCE" function used in GCMs, but the essence of this kind of uncertainty is the round-off error. With the change of the CPU numbers, computation sequence will change accordingly due to the "MPI_ALLREDUCE" used in the model. Commutative law does not work when there exists the round-off error during the numerical computation. So, the difference of model results comes out in this way, and is amplified by nonlinear interactions. Although the round-off error change due to "MPI_ALLREDUCE" could be avoided and then the parallel model results of GCMs are the same with those of the serial model, we cannot guarantee the results of the serial model have no uncertainty, because the serial model also contains the round-off error. In addition, the round-off error also has influence on the model results in the similar way when the computing environment is changed, such as different computing architectures or compiler optimizations. So we can design numerical experiments to mimic the round-off error by changing the CPU's configuration.

Since a large amount of computation resource is required to simulate climate variability by using CGCMs and the computation is limited, it is very common to change the CPU configuration during a long-term model run. Therefore, it is important for us to know the usability and applicability of the models' simulation uncertainty caused by the parallel computational error. In other words, can the uncertainty by the parallel computational error be ignored when we use CGCMs to simulate climate variations on different timescales? In the present paper, we use the CCSM3 (Collins et al., 2006a) model as an example to explore and investigate the effect of the parallel computational uncertainty on climate simulations. Our focus is on the simulated SST, with the aim to gain a better understanding on how the simulation could be used rationally.

The paper is organized as follows: Sect. 2 briefly describes the CCSM 3 and experimental designs. Section 3 shows the impact of the parallel computational uncertainty on the global and Nino3.4 SSTs. Finally, Sect. 4 gives the conclusion and discussion.

\section{Model description and experimental designs}

The CCSM3, which was released to the public by the National Center for Atmospheric Research (NCAR) in June 2004 , is one of the state-of-art climate models for simulating the Earth's climate. It consists of four dynamical geophysical models (i.e., the atmosphere, ocean, land and sea ice) linked by a central coupler. The coupler exchanges fluxes and state information among the above four components by the MPI technique. The atmosphere, ocean, land and ice components of CCSM3 are the NCAR Community Atmospheric Model Version 3 (CAM3), the Parallel Ocean Program Version 1.4.3 (POP1.4.3), the NCAR Community Land
Table 1. Computer configuration.

\begin{tabular}{ll}
\hline & HP Superdome Workstation \\
\hline Hardware & 128-core 1.66 GHz Itanium2 IA64 CPU \\
OS & HP-UX B.11.23 \\
Fortran Compiler & HP F90 V3.0 \\
C Compiler & HP c/aC++ A.06.15 \\
MPI & HP-MPI A.06.15 for HP-UX \\
\hline
\end{tabular}

Table 2. Experiments descriptions.

\begin{tabular}{|c|c|c|c|c|c|c|c|}
\hline \multirow[b]{2}{*}{ Component } & \multicolumn{3}{|c|}{ Experiment 1 (16 cases) } & \multicolumn{4}{|c|}{ Experiment 2 (54 cases) } \\
\hline & & $\begin{array}{l}\text { PU } \\
\text { nbers }\end{array}$ & $\begin{array}{l}\text { Simulation } \\
\text { length (yr) }\end{array}$ & & $\begin{array}{l}\mathrm{CP} \\
\mathrm{umb}\end{array}$ & & $\begin{array}{l}\text { Simulation } \\
\text { length (yr) }\end{array}$ \\
\hline Land Surface & 2 & - & 100 & 2 & - & - & 10 \\
\hline Atmosphere & 2 & 4 & 100 & 2 & 4 & - & 10 \\
\hline Sea Ice & 2 & 4 & 100 & 2 & 4 & 6 & 10 \\
\hline Ocean & 4 & 8 & 100 & 4 & 8 & 12 & 10 \\
\hline Coupler & 2 & 4 & 100 & 2 & 4 & 6 & 10 \\
\hline
\end{tabular}

Model Version 3 (CLM3), and the NCAR Community Sea Ice Model Version 5 (CSIM5), respectively. More technical details about CCSM3, CAM3, POP, CLM3, and CSIM5 can be found in Vertenstein et al. (2004), Collins et al. (2004), Smith and Gent (2004), Dickinson et al. (2006) and Briegleb et al. (2004).

In this study, the CCSM3 configuration is referred to as "compset B -res T31_gx3v5" (Vertenstein et al., 2004). This means the horizontal resolutions are the T31 spectral truncation for both CAM3 (Collins et al., 2006b) and CLM3 (Dickinson et al., 2006) and a nominal 3-degree for CSIM5 (Briegleb et al., 2004) and POP1.4.3 (Simith et al., 2002). The machine used in our study is the HP Superdome Workstation (Table 1).

As we know, the multi-year climatological mean and ensemble mean are common methods used in the climate research. We thus design two groups of experiments (Table 2) for studying these two methods. According to the CCSM3 manual (Vertenstein et al., 2004) and previous research (Chen et al., 2008), the simulated results depend on the CPU numbers of each component except the surface land model component. Therefore, we would like to design different experiment cases by changing the CPU numbers used in each component. Considering both the representative of the parallel computational error and the computational resource, we designed 16 cases in which the model is run for $100 \mathrm{yr}$ of the multi-year climatological mean (Experiment 1, Table 2), and 54 cases in which the model is run for $10 \mathrm{yr}$ of the ensemble mean (Experiment 2,Table 2). All of the model outputs are the monthly average. These experiments represent any combinations of different CPU number with each component 
Z. Song et al.: Influence of parallel computational uncertainty

315

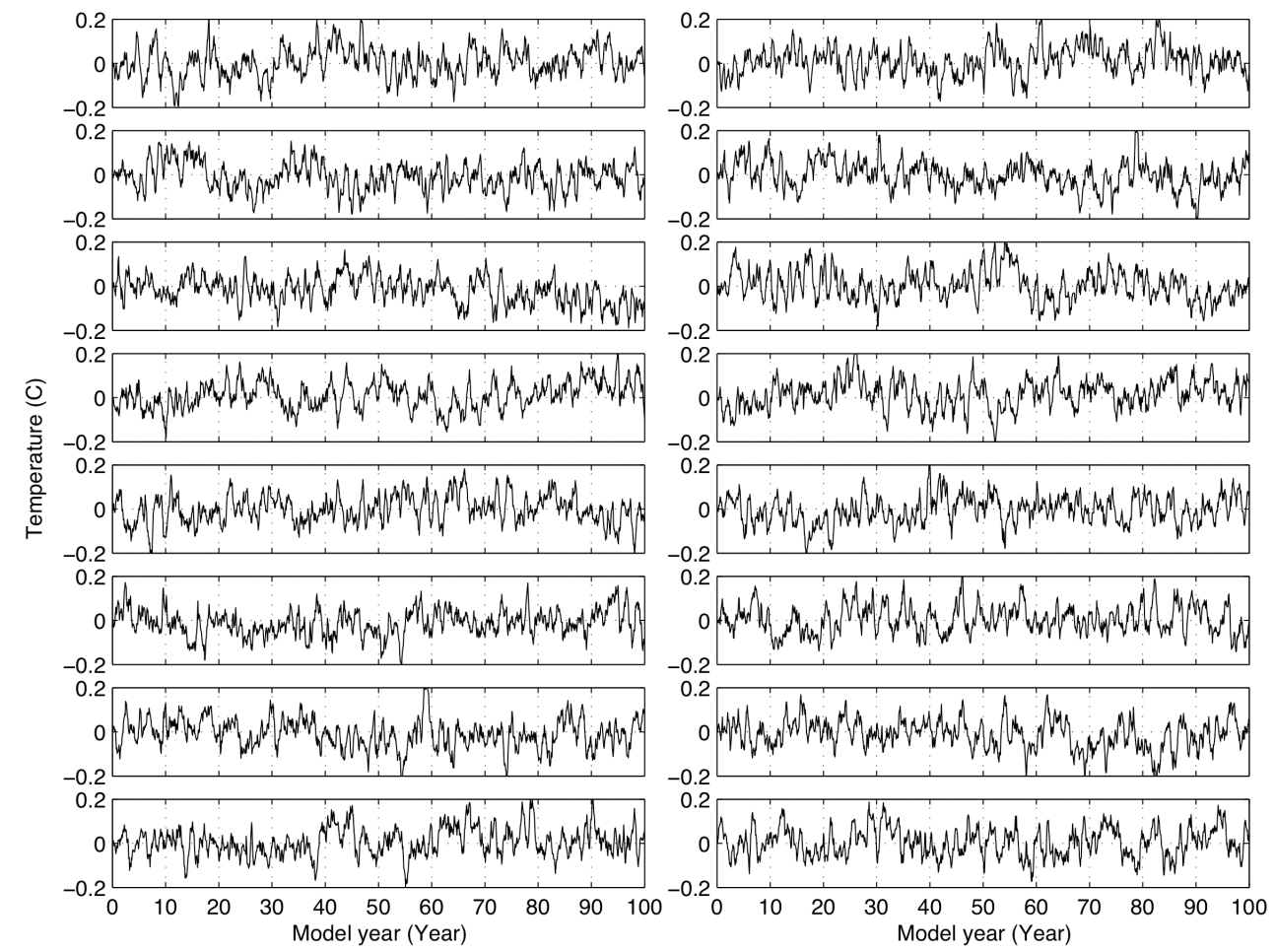

Fig. 1. Deviations of the Global-SST for 16 cases in Experiment 1.

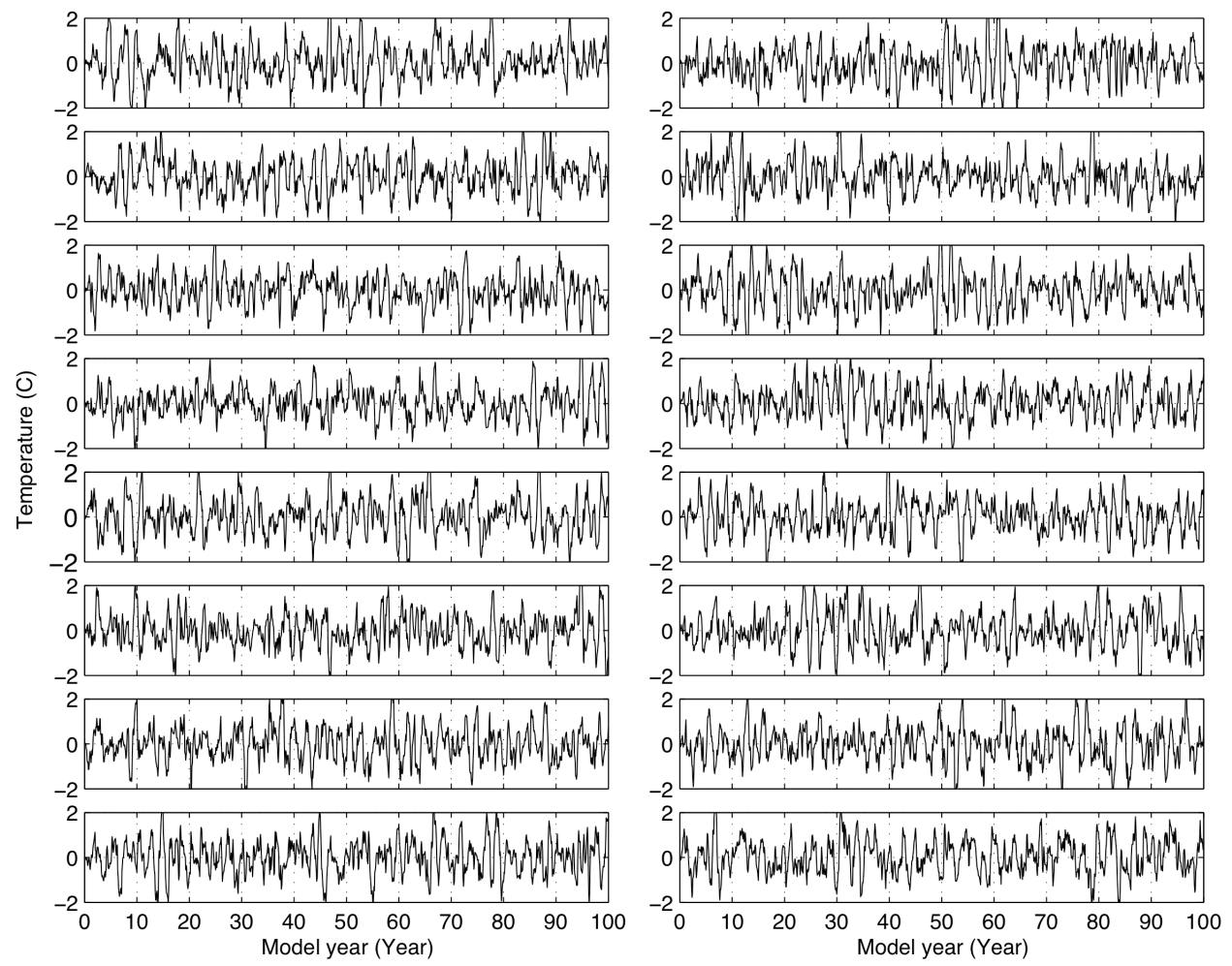

Fig. 2. Deviations of the Nino-SST for 16 cases in Experiment 1.

www.geosci-model-dev.net/5/313/2012/

Geosci. Model Devi., 5, 313-319, 2012 

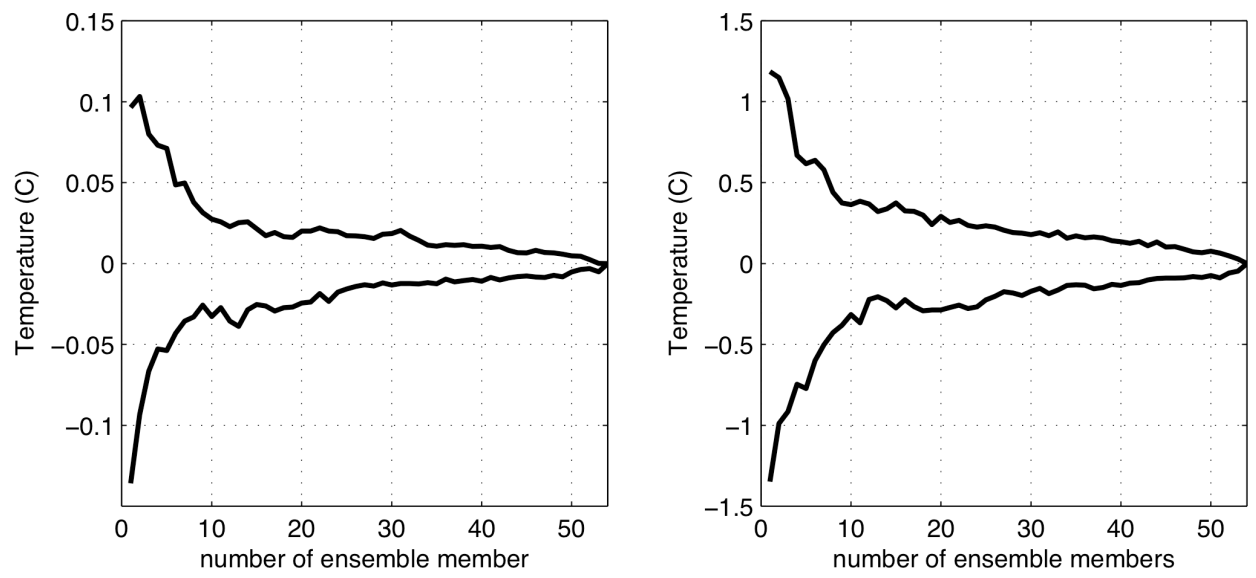

Fig. 3. The evolution of maximum and minimum Global-SST (left) and Nino-SST (right) deviation with the number of ensemble members.

and have prominent representativeness for the analysis of the parallel computational uncertainty.

\section{Analyses and results}

SST is an important parameter to measure the coupled model simulations since it is in the interface of the ocean and atmosphere and plays a key role in the ocean and atmosphere interaction for shaping climate variability. In this paper, we analyzed the influence of the parallel computational uncertainty on the simulated SST. We chose the global average SST (Global-SST) for representing the global simulation, and Nino3.4 SST (Nino-SST) for manifesting variability in the equatorial central/eastern Pacific where the oceanatmosphere interaction is one of the strongest regions in the climate system.

From the model-simulated perspective, there is no exactly true value in the climate simulation. In order to clearly describe and compare the experiment results, we define a standard value and a deviation as:

$$
\begin{aligned}
& \bar{X}=\frac{1}{N} \sum_{i=1}^{N} X_{i} \\
& D_{i}=X_{i}-\bar{X}, i=1,2, \cdots, N
\end{aligned}
$$

where $\bar{X}$ is the standard value, and $D_{i}$ is the deviation between simulation and the standard value. $X_{i}$ is the case's simulations in two experiments, and $N$ is the number of cases in two experiments (which is 16 and 54 in Experiments 1 and 2 , respectively).

\subsection{Results with the Monthly Time Series}

The time series of a variable is often used to reflect climate variations in climate research. Here, we first diagnose the impact of the parallel computational error on the monthly time series. The deviations of the Global-SST and Nino-SST for 16 cases in Experiment 1 are shown in Fig. 1 and Fig. 2, respectively. The deviation of the Global-SST is $\pm 0.2{ }^{\circ} \mathrm{C}$, while the deviation of the Nino-SST can reach $\pm 2.0^{\circ} \mathrm{C}$. The amplitude of the deviation induced by the parallel computational uncertainty is in the same order as that of the climate system change. Furthermore, a comparison of each subfigure shows that the deviation is not the same with each other. We also checked the model runs from Experiment 2 showing a consistent result (not shown). Therefore, the uncertainty due to the parallel computational error has a major impact on the monthly time series. The influence cannot be ignored if the computing platform or the CPU distribution scheme used by CGCMs is changed. A determination of the reliability of the simulated time series is needed, especially for a climate jump or shift phenomenon.

The ensemble mean is a common method to eliminate the uncertainty in the forecast. The question is whether the ensemble mean can reduce the parallel computational uncertainty in climate simulations. The maximum and minimum deviations change as a function of the member numbers of the ensemble mean, which is shown in Fig. 3. For both the Global-SST and Nino-SST, the deviations decrease as the numbers increase. It is noticed that when the member number of the ensemble mean is less than 15 , the deviations decrease rapidly and therefore, the change of the deviation is very steep. The maximum deviation of the Global-SST decreased from 0.1 to 0.03 , while the minimum changes from -0.14 to -0.03 . For the Nino-SST, the maximum deviation decreased from 1.2 to 0.4 , whereas the minimum changes from -1.4 to -0.4 . In contrast, when the average number is larger than 15 , the deviations decrease slowly and their changes are almost a constant. This indicates that the increase of the ensemble mean number has a small effect if the number is already larger than 15 . Thus, we can conclude that the ensemble mean can reduce the parallel computational 

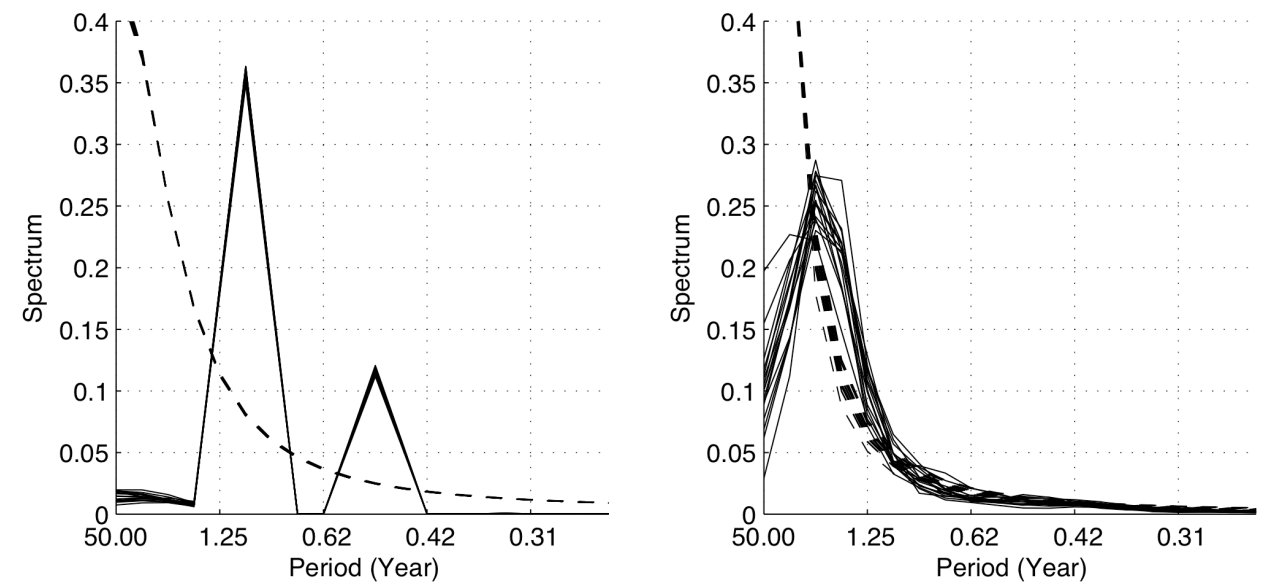

Fig. 4. The power spectrums of Global-SST (left) and Nino-SST (right) for 16 cases in Experiment 1.
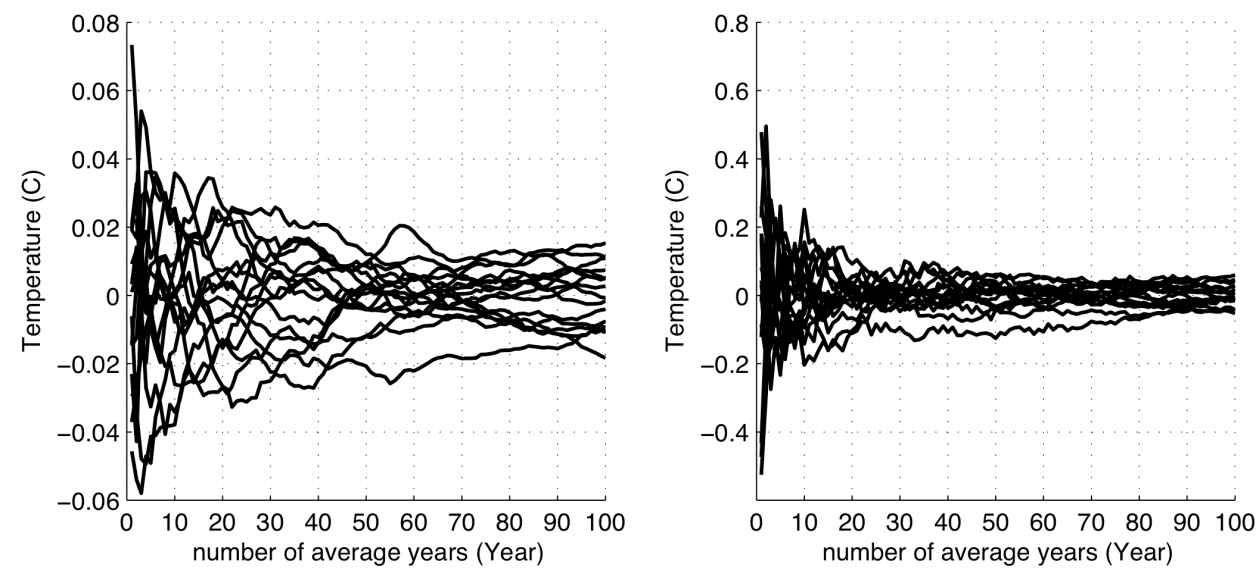

Fig. 5. The evolution of maximum and minimum Global-SST (left) and Nino-SST (right) deviation with the number of average years in climatology.

uncertainty and a more average number is better, but the ensemble mean number of 15 is enough for the sake of saving computation resource.

\subsection{Impact on simulated periods}

The simulated period of a climate signal is very important since it can help us understand climate variability and improve climate prediction. A natural question is does the parallel computational uncertainty affect the simulated climatic periods? The power spectrums of the Global-SST and NinoSST for 16 cases of Experiment 1 are shown in Fig. 4. For the Global-SST, all of the 16 power spectrums are almost identical (Fig. 4a), with two peaks at the annual and semiannual timescales (with $99 \%$ confidence interval). All of the 16 power spectrums for the Nino-SST peak around the 2.5yr (with $99 \%$ confidence interval) timescale (Fig. 4b). These indicate that all of the experiment cases are able to simulate the periods of climate signals and that the parallel computational uncertainty does not affect simulated periods. It should be mentioned that the 16 power spectrums for Nino-SST are not identical although their main characters are quite similar. Maybe, it is because the global mean SST is quite steady, while Nino-SST normally has quite large variability.

\subsection{Results with the climatological mean}

The climatological mean or climatology is also common to use for representing the seasonal cycle. In this subsection, we investigate the influence of the parallel computational uncertainty on climatology. Figure 5 shows the changes of the annual mean Global-SST and Nino-SST deviation as a function of the number of the average years. The $\mathrm{x}$-axis is the number of average years, so the number of 100 represents 
the climatological mean used 100yr data. As seen in Fig. 5, the deviation is very large with a small number of average years. The amplitudes of the Global-SST and Nino-SST deviations are $0.12{ }^{\circ} \mathrm{C}$ (varying from -0.0 .4 to 0.08 ) and $1.0^{\circ} \mathrm{C}$ (from -0.5 to 0.5 ), respectively. With increasing the number of average years, the ranges of the annual mean Global-SST and Nino-SST deviation decrease and concentrate in small ranges that are only $0.04^{\circ} \mathrm{C}$ and $0.1{ }^{\circ} \mathrm{C}$. When the climatological mean is averaged by using more than $30-y r$ data, these small ranges of the deviations can be ignored (which can be regarded as within the measurement error range). Thus, the impact of the parallel computational error on the climatological mean can be ignored if we use more than $30 \mathrm{yr}$ data for the average.

\section{Discussion and conclusion}

We designed the parallel computational uncertainly experiments to mimic the round-off error due to using different CPU configuration based on the state-of-art climate model of CCSM3. For the monthly time series of Global-SST and Nino-SST, the results show that the influence of the parallel computational uncertainly on model simulations cannot be ignored if the computing platform or the CPU distribution scheme used by CGCMs is changed. However, the ensemble mean method is able to reduce the impact of the parallel computational uncertainty and the member number of the ensemble mean of 15 is enough to ignore simulated error. The random perturbation experiments also show similar results (Z. Y. Song, personal communication, 2011). The parallel computational uncertainly can affect the climatology results, but it can be ignored if we use more than 30-yr data to average the climatological mean. The power spectrum analyses show that the parallel computational uncertainty does not largely affect the period of climate signal. Finally, it is suggested that the influence of the parallel computational uncertainty on the CGCMs can be a quality standard or a metric for developing CGCMs.

The present paper uses CCSM3 to show the influence of the parallel computational uncertainty on simulations of the coupled system. Although we believe that the results can be applied to other models, a future study needs confirm that the results are model-independent. In addition, the present paper mainly focuses on global and Nino3.4 average SST, and other regions or variables such as precipitation and radiative flux need to be investigated in the future.

Acknowledgements. This work was supported by the National Basic Research Program of China (973 Program) through grant 2010CB950500, the Key Project of National Natural Science Foundation of China through grant 40730842, the Project of National Natural Science Foundation of China through grant 40906018 and the Key Supercomputing Science-Technology Project of Shandong Province of China through grant 2011YD01107.

Edited by: J. Annan

\section{References}

Briegleb, B. P., Bitz, C. M., Hunke, E. C., Lipscomb, W. H., Holland, M. M., Schramm, J. L., and Moritz, R. E.: Scientific description of the sea ice component in the Community Climate System Model, Version Three. NCAR Tech. Rep. NCAR/TN463+STR, National Center for Atmospheric Research, Boulder, CO, 78 pp., 2004.

Chen, X. Y., Song, Z. Y., Zhao, W., Wang, G. S., and Qiao, F. L.: Uncertainty analysis of results simulated by climate model system, Adv. Mar. Sci., 26, 119-125, 2008 (in Chinese).

Collins, W. D., Rasch, P. J., Boville, B. A., Hack, J. J., McCaa, J. R., Williamson, D. L., Kiehl, J. T., Briegleb, B., Bitz, C., Lin, S.-J., Zhang, M., and Dai, Y.: Description of the NCAR Community Atmosphere Model (CAM 3.0), NCAR Tech. Rep. NCAR/TN464+STR, National Center for Atmospheric Research, Boulder, CO, 210 pp., 2004.

Collins, W. D., Bitz, C. M., Blackmon, M. L., Bonan, G. B., Bretherton, C. S., Carton, J. A., Chang, P., Doney, S. C., Hack, J. J., Henderson, T. B., Kiehl, J. T., Large, W. G., McKenna, D. S., Santer, B. D., and Smith, R. D.: The Community Climate System Model version 3 (CCSM3), J. Climate, 19, 2122-2143, 2006a.

Collins, W. D., Rasch, P. J., Boville, B. A., Hack, J. J., McCaa, J. R., Williamson, D. L., and Briegleb, B. P.: The formulation and atmospheric simulation of the Community Atmosphere Model Version 3 (CAM3), J. Climate, 19, 2144-2161, 2006b.

Cousins, S., and Xue, H.: Running the POM on a Beowulf Cluster. 2001 Terrain-Following Coordinates User's Workshop, Boulder, Colorado, USA, ONR Ocean Modeling and Prediction Program, Boulder, Colorado, http://www.myroms.org/ Workshops/TOMS2001/presentations/Steve.Cousins.ppt., 20-22 August, 2001.

Dickinson, R. E., Oleson, K. W., Bonan, G., Hoffman, F., Thornton, P., Vertenstein, M., Yang, Z.-L., and Zeng, X.: The Community Land Model and its climate statistics as a component of the Community Climate System Model, J. Climate, 19, 2302-2324, 2006

Dorn, W., Dethloff, K., Rinke, A., Frickenhaus, S., Gerdes, R., Karcher, M., and Kauker, F.: Sensitivities and uncertainties in a coupled regional atmosphere-ocean-ice model with respect to the simulation of Arctic sea ice, J. Geophys. Res., 112, D10118, doi:10.1029/2006JD007814, 2007.

Held, H., Knopf, B., Schneiderd von Deimling, T., and Schellnhuber, H.-J.: Uncertainty analysis of model coupling, Abstract\# 4456, EGS XXVII General Assembly, Nice, France, available at http://adsabs.harvard.edu/abs/2002EGSGA..27.4456H, 21-26 April, 2002.

Meehl, G. A., Stocker, T. F., Collins, W. D., Friedlingstein, P., Gaye, A. T., Gregory, J. M., Kitoh, A., Knutti, R., Murphy, J. M., Noda A., Raper, S. C. B., Watterson, I. G., Weaver, A. J., and Zhao, Z.-C.: Global Climate Projections, In: Climate Change 2007: The Physical Science Basis, Contribution of Working Group I to the Fourth Assessment Report of Intergovermental Panel on Climate Change, edited by: Solomon, S., Qin, D., Manning, M., Chen, Z., Marquis, M., Averyt, K. B., Tignor, M., and Miller, H. L., Cambridge University Press, Cambridge, UK and New York, NY, USA, 747-845, 2007.

Moss, R. and Schneider, S.: Uncertainties. Guidance Papers on the Cross Cutting Issues of the Third Assessment Report of the IPCC, edited by: Pachauri, R., T. Taniguchi, T., and Tanaka K., Intergovernmental Panel on Climate Change, Geneva, 33-51, 
2000.

Smith, R. D. and Gent, P. R.: Reference manual for the Parallel Ocean Program (POP), ocean component of the Community Climate System Model (CCSM2.0 and 3.0), LANL Tech. Rep. LA-UR-02-2484, Los Alamos National Laboratory, available at http://www.ccsm.ucar.edu/models/ccsm3.0/pop, May 2002, revised May 2004.

Tebaldi, C., Nychka, K., and Mearns, L.: From global mean responses to regional signals of climate change: Simple pattern scaling, its limitations (or lack of) and the uncertainty in its results, the 17th Conference on Probability and Statistics in the Atmospheric Sciences, AMS Annual Meeting, Seattle, WA, available online at http://ams.confex.com/ams/pdfpapers/69656.pdf, 10-15 January, 2004.
Wang, P. F., Wang, Z. Z., and Huang, G.: The Influence of round-off error on the Atmospheric General Circulation Model, Chinese J. Atmos. Sci., 31, 815-825, 2007 (in Chinese).

Wittenberg, A. T. and Anderson, J. L.: Dynamical implications of prescribing part of a coupled system: Results from a low-order model, Nonlin. Processes Geophys., 5, 167-179, doi:10.5194/npg-5-167-1998, 1998.

Vertenstein, M., Craig, T., Henderson, T., Murphy, S., Jr, G., and Norton, N.: CCSM3 user's guide, National Center for Atmospheric Research, Boulder, CO, $69 \mathrm{pp}$., available at: http://www.cesm.ucar.edu/models/ccsm3.0/ccsm/doc/ UsersGuide/UsersGuide.pdf, 25 June, 2004. 